\title{
Effect of Orifice Diameter of Torch Injector Tube in Inductively Coupled Plasma Mass Spectrometry
}

\author{
Tomokazu TaNaKa, Yasushi SakaI and Hiroshi Kawaguchi \\ Department of Materials Science and Engineering, Nagoya University, Nagoya 464-01, Japan
}

Keywords Inductively coupled plasma mass spectrometry, torch, oxide ion, plasma operating condition, inductively coupled plasma atomic emission spectrometry

Since the first commercial instruments for inductively coupled plasma mass spectrometry (ICP-MS) became available, remarkable improvements in the instrument and enhancement of the sensitivity have been achieved. The plasma torch, however, has been used with almost the same configuration as that was used originally in ICP atomic emission spectrometry (ICP-AES). A few studies ${ }^{1,2}$ evaluated ICP torches with different sizes for use in ICPMS, but no systematic study has been carried out for the effect of the torch configuration. Although the application of water-cooled ${ }^{3,4}$ or mini $^{5}$ torches to ICP-MS has been attempted, the main purpose of these studies was the reduction of the Ar gas consumption.

In the present study, a torch with a demountable injector tube was constructed in order to investigate the effect of only the orifice diameter of the injector tube on ion signals. When we increased the orifice diameter of the injector tube, an increase in the intensities of analyte ions and a decrease in the analyte oxide ions were observed.

\section{Experimental}

\section{Torch with a demountable injector tube}

A schematic diagram of the torch with a demountable injector tube is shown in Fig. 1. This torch has a similar shape and size to those of the conventional torch, except that the injector tube is fixed with a ground-glass joint.

Injector tube

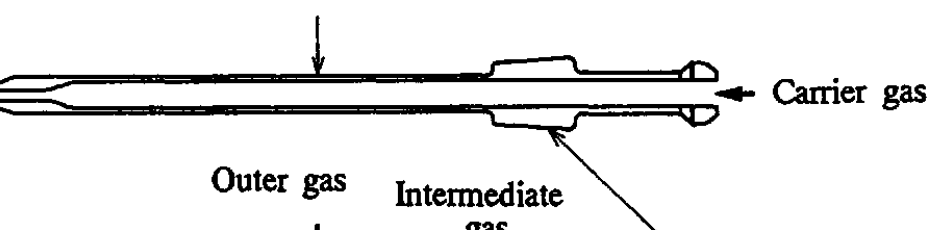

Stainless rod

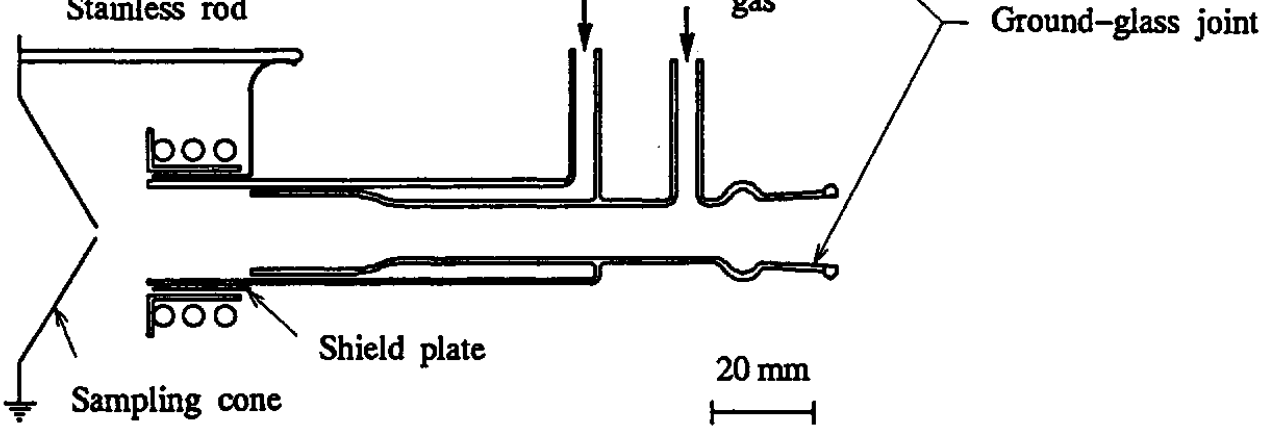

Fig. 1 Schematic diagram of the torch with a demountable injector tube. 
Therefore, the effect of only the orifice diameter of the injector tube on ion signals can be studied. Five injector tubes with orifice diameters of $0.9,1.3,1.8,2.2$ and $2.5 \mathrm{~mm}$ were constructed. The conventional torch has an injector tube with a $1.8 \mathrm{~mm}$ orifice diameter.

\section{Instruments and sample solution}

A commercial ICP mass spectrometer (SPQ 6500, Seiko Instr. Inc.) was used. An electrostatic shielding plate was inserted into the gap between the torch and the work coil, as described elsewhere. ${ }^{6}$

A sample solution containing $1 \mathrm{ng} / \mathrm{ml}$ of $\mathrm{Co}$ and $\mathrm{La}$, as well as $1 \%$ nitric acid, was prepared by diluting the stock solutions with pure water just before measurements.

A conventional concentric nebulizer and double pass spray chamber were employed. Ion signal intensities were measured in the peak hopping mode: dwell time $100 \mathrm{~ms}$, channel width 3 , accumulation 5 times and repetition 2 times.

\section{Results and Discussion}

Effects of the plasma operating parameters on ion signal intensities

It is well known that the most important parameters affecting the signal intensities in ICP-MS are carrier gas flow rate, sampling depth and RF power. ${ }^{7}$ Under the optimum conditions for the conventional torch (i.e., carrier gas flow rate : $1.10 \mathrm{l} / \mathrm{min}$, sampling depth : $12 \mathrm{~mm}$, RF power : $1.2 \mathrm{~kW}$ ), the variations of $\mathrm{Co}^{+}$signal intensity as a function of these parameters are shown in Fig. 2 for three injector tubes. These figures show that the diameter of the
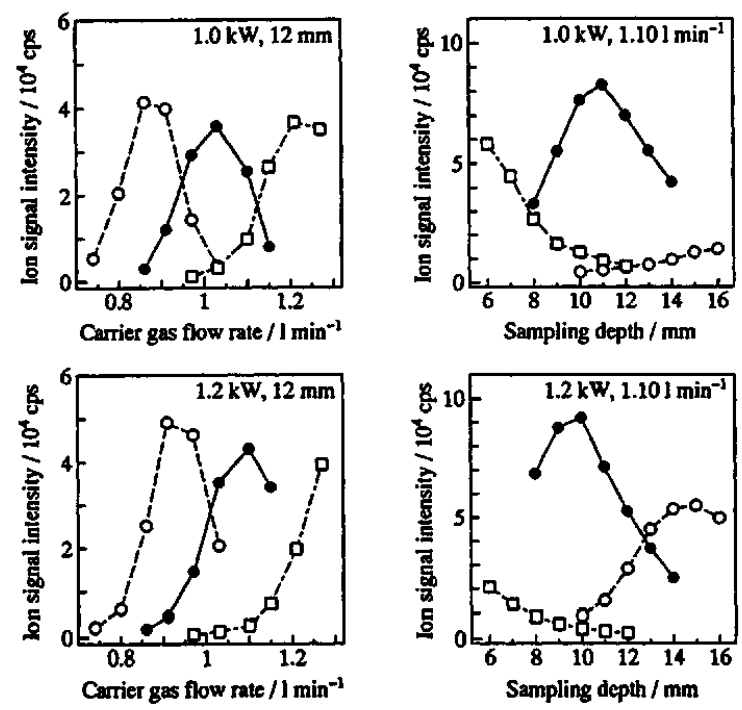

Fig. 2 Variation of $\mathrm{Co}^{+}$signal intensity as a function of carrier gas flow rate and sampling depth. Diameter of the injector tube; $O: 1.3 \mathrm{~mm}, O: 1.8 \mathrm{~mm}, \square: 2.2 \mathrm{~mm}$
Table 1 Optimum operating conditions for each injector tube

\begin{tabular}{cccc}
\hline $\begin{array}{c}\text { Orifice dia. } \\
\text { mm }\end{array}$ & $\begin{array}{c}\text { RF power } \\
\mathrm{kW}\end{array}$ & $\begin{array}{c}\text { Carrier gas } \\
\mathrm{l} \mathrm{min}^{-1}\end{array}$ & $\begin{array}{c}\text { Sampling depth } \\
\mathrm{mm}\end{array}$ \\
\hline 0.9 & 1.2 & 0.80 & 11 \\
1.3 & 1.2 & 0.97 & 11 \\
1.8 & 1.2 & 1.10 & 10 \\
2.2 & 1.2 & 1.21 & 8 \\
2.5 & 1.2 & 1.27 & 7 \\
\hline
\end{tabular}

injector tube affects significantly the carrier gas flow rate and the sampling depth where the maximum $\mathrm{Co}^{+}$intensity appears. The larger the diameter is, the higher the flow rate and the lower the sampling depth becomes.

Operating conditions for the maximum signal intensities

In order to determine the optimum operating conditions for each injector tube, $\mathrm{Co}^{+}$and $\mathrm{La}^{+}$signals were measured by varying the $R F$ power $(0.8-1.6 \mathrm{~kW})$, carrier gas flow rate $(0.74-1.59 \mathrm{l} / \mathrm{min})$ and sampling depth $(5-25 \mathrm{~mm})$, independently. Since these parameters are related to each other for the ion signals, each value of the parameters was scanned several times (roughly and finely) to obtain the maximum signal intensities for each injector tube. The resulted optimum conditions are summarized in Table 1. The RF power was optimum at $1.2 \mathrm{~kW}$ independent of the orifice diameter, while the optimum carrier gas flow rate became higher and the sampling depth lower with increasing orifice diameter.

Behavior of oxide ion signals for different injector tubes

The effect of various parameters on $\mathrm{La}^{+}$intensity and $\mathrm{LaO}^{+} / \mathrm{La}^{+}$ratio is shown in Fig. 3 for three injector tubes. In these experiments, the operating conditions in Table 1 were used other than the variables. The behavior of the signals for each parameter is similar for different orifice diameters, although the optimum carrier gas flow rate and sampling depth are different.

Table 2 shows the signal intensities of $\mathrm{Co}^{+}$and $\mathrm{La}^{+}$as well as the ratios of $\mathrm{LaO}^{+} / \mathrm{La}^{+}$and $\mathrm{La}^{2+} / \mathrm{La}^{+}$measured under the optimum conditions for each injector tube. Intensities of $\mathrm{Co}^{+}$and $\mathrm{La}^{+}$increase with increasing orifice diameter of the injector tube, but they saturate at $2.2 \mathrm{~mm}$ diameter. Considering that the diameter of the conventional torch is $1.8 \mathrm{~mm}$, the enhancement of the signal intensity by increasing the diameter is not significant.

On the other hand, the $\mathrm{LaO}^{+} / \mathrm{La}^{+}$ratio decreases with the increase in the orifice diameter. Calculation of the linear velocity of the carrier gas which leaves the tip of the injector tube at room temperature shows that the velocity for the $2.5 \mathrm{~mm}$ tube $(0.43 \mathrm{~m} / \mathrm{s})$ is $c a$. one fifth to that for $0.9 \mathrm{~mm}(2.10 \mathrm{~m} / \mathrm{s})$. The decrease of $\mathrm{LaO}^{+} / \mathrm{La}^{+}$ratio probably resulted from the increase in the residence time of the sample aerosol in the plasma and also from the 
a) $1.3 \mathrm{~mm}$

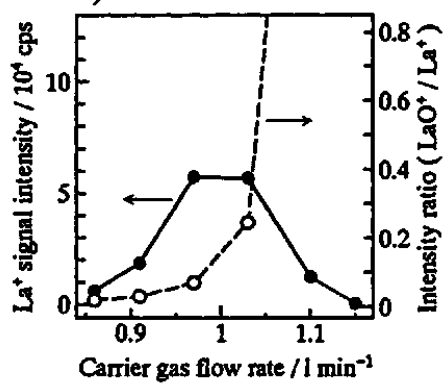

b) $1.8 \mathrm{~mm}$

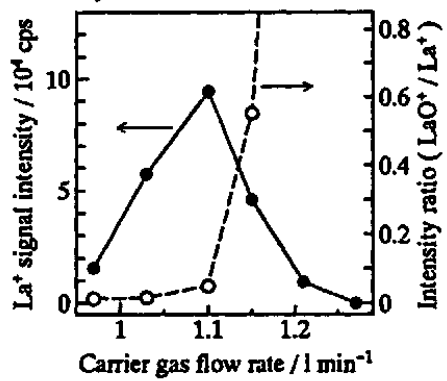

c) $2.2 \mathrm{~mm}$

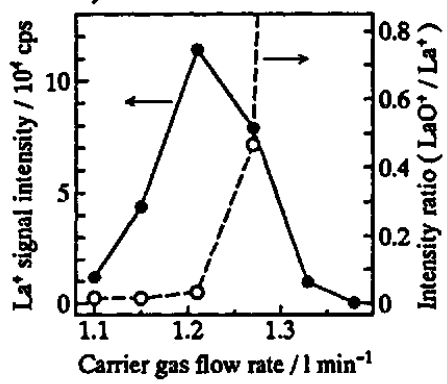

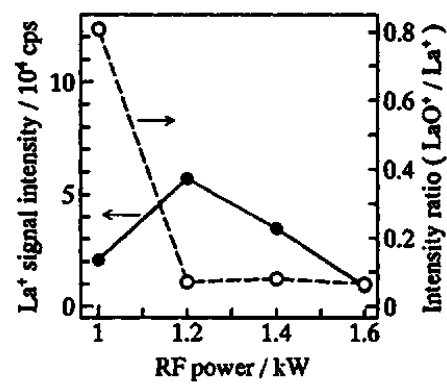
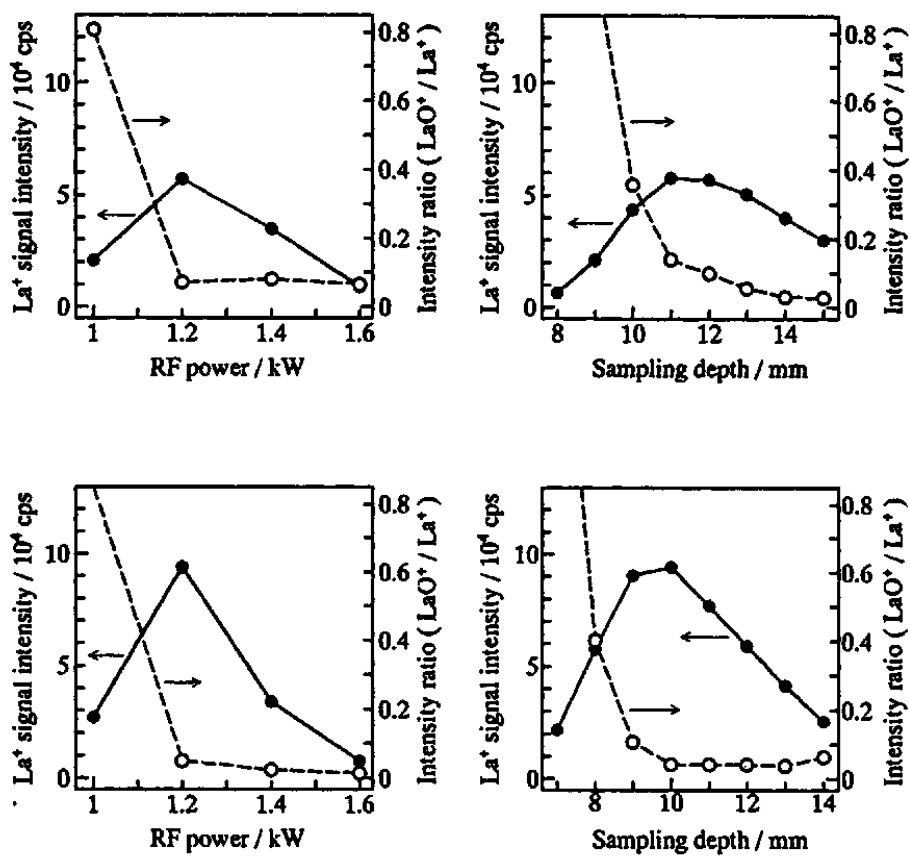

Sampling depth / mm

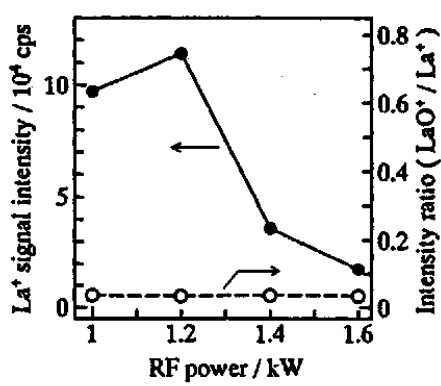

Fig. 3 Variation of $\mathrm{La}^{+}$and $\mathrm{LaO}^{+} / \mathrm{La}^{+}$as a function of various operating parameters under optimum conditions for $1.3,1.8$ and $2.2 \mathrm{~mm}$ injector tubes.

Table 2 Comparison of ion signal intensities obtained under optimum conditions for each injector tube

\begin{tabular}{ccccc}
\hline $\begin{array}{c}\text { Orifice dia. } \\
\mathrm{mm}\end{array}$ & $\begin{array}{c}\mathrm{Co}^{+} \\
\times 10^{4} \mathrm{cps}\end{array}$ & $\begin{array}{c}\mathrm{La}^{+} \\
\times 10^{4} \mathrm{cps}\end{array}$ & $\begin{array}{c}\mathrm{LaO}^{+} / \mathrm{La}^{+} \\
\%\end{array}$ & $\begin{array}{c}\mathrm{La}^{2+} / \mathrm{La}^{+} \\
\%\end{array}$ \\
\hline 0.9 & 6.2 & 5.5 & 13.9 & 0.23 \\
1.3 & 6.2 & 5.7 & 6.87 & 0.18 \\
1.8 & 9.7 & 9.4 & 4.99 & 0.21 \\
2.2 & 10.7 & 11.4 & 3.32 & 0.14 \\
2.5 & 10.1 & 12.0 & 1.71 & 0.17 \\
\hline
\end{tabular}

avoidance of a cooling effect at the central channel. The $\mathrm{La}^{2+} / \mathrm{La}^{+}$ratio shows no systematic change with the variation of the orifice diameter. This is due to the reduction of the plasma potential by the electrostatic shielding plate, and consequently, the suppression of the secondary discharge at the sampling orifice. ${ }^{4,6,8}$ The difference of the orifice diameter did not largely affect the intensities of polyatomic ions from $\mathrm{Ar}$ (e.g., $\mathrm{ArC}^{+}, \mathrm{ArN}^{+}$, $\mathrm{ArO}^{+}$and $\mathrm{Ar}_{2}{ }^{+}$).

The results of this study show that a torch having a larger orifice diameter of the injector tube is effective to reduce the oxide ions, but not extremely effective to 
enhance the signal intensities. Therefore, the torch may be useful for the analysis of complex samples containing elements which easily form oxide ions, such as rare earth elements.

The authors thank Mr. T. Watanabe of Nagoya University for manufacturing the torch with a demountable injector tube.

\section{References}

1. B. S. Ross, P. Yang and G. M. Hieftje, Appl. Spectrosc., 45, 190 (1991).

2. L. A. Norman, M. Munoz, D. P. Myers, B. S. Ross and G. M. Hieftje, Appl. Spectrosc., 46, 448 (1992).
3. J. S. Gordon, P. S. C. van der Plas and L. DeGalan, Anal. Chem, 60, 375 (1988).

4. T. Tanaka, K. Yonemura, M. Tanabe and H. Kawaguchi, Anal. Sci., 7, 537 (1991).

5. B. S. Ross, D. M. Chambers, G. H. Vickers, P. Yang and G. M. Hieftje, J. Anal. At. Spectrom., 5, 351 (1990).

6. N. S. Nonose, N. Matsuda, N. Fudagawa and M. Kubota, Spectrochim. Acta, 49B, 955 (1994).

7. M. A. Vaughan, G. Horlick and S. H. Tan, J. Anal. At. Spectrom., 2, 765 (1987).

8. K. Sakata and K. Kawabata, Spectrochim. Acta, 49B, 1027 (1994).

(Received April 13, 1995)

(Accepted July 10, 1995) 